\title{
Computer Modeling Approach of Leachate Flow in Compacted Laterite Soil Liner
}

\author{
Yamusa Bello Yamusa ${ }^{1,2}$, Noraliani Alias ${ }^{1}$, Kamarudin Ahmad $^{1 *}$, Radzuan Sa'ari $^{1}$, Loke \\ Kok Foong ${ }^{1}$ \\ ${ }^{1}$ Faculty of Civil Engineering, Universiti Teknologi Malaysia, 81310 Skudai, Johor, Malaysia \\ ${ }^{2}$ Department of Civil Engineering, Nuhu Bamalli Polytechnic, 810001 Zaria, Nigeria
}

\begin{abstract}
The use of hydraulic barriers in sanitary landfills has become an impeccable means of protecting the groundwater system from leachate. A question to be asked is, can these barriers continue to impede the migration of leachate over a long period? This paper investigates the phenomenon of leachate migration in compacted laterite soil used as liner in sanitary landfills. An experiment was carried out using laterite soil compacted at optimum moisture content using Standard Proctor energy. Leachate was poured on the compacted soil in an acrylic column and its migration was monitored using Digital Image Technique (DIT). The DIT capture photographic images at successive intervals of time which were fed through an image processing code to convert them to hue-saturationintensity (HSI) format with the help of Surfer and Matlab computer softwares. Subsequently, PetraSim computer software was applied to predict the velocity behavior. The predicted velocity value shows that the laterite soil is compatible with the leachate and can be used as soil liner. The outcome of this study would enable designers to use non-destructive method to monitor and predict leachate migration in compacted soil liners to simulates leachate migration in waste containment applications.
\end{abstract}

\section{Introduction}

Computer modeling approach of groundwater flows and transport systems has become imperative. The groundwater management, policy making and planning processes support an important practice which involve the use of groundwater modeling. These models provide a systematic background for understanding the mechanisms of groundwater systems and the procedures that effect their quality. Progressively, models are an integral part of water resources assessment, protection and restoration studies, and provide essential and cost-effective support for planning and screening of alternative policies, regulations, and engineering designs affecting groundwater [1].

Before remediating contaminated groundwater of a specified field, it is necessary to understand the physical, chemical and biological processes that occur in the field. By translating these processes into mathematical terms, groundwater modelling is a tool

\footnotetext{
Corresponding author: kamarudin@utm.my
} 
designed to represent a simplified version of a real field site, and therefore allows to understand and predict the system and its behaviour. The resulting model is only as good as the conceptual understanding of the processes. The goal of modeling is to predict the value of an unknown variable such as head in an aquifer system or the concentration distribution of a given chemical in the aquifer in time and space. Modeling groundwater contaminant transport involves three initial considerations [2]; model selection (development of a conceptual model and translation of this conceptual model into mathematical model), solution technique (analytical or numerical model), and input data. The conceptual model consists of a description of the physical, chemical, and biological processes which are thought to be governing the behaviour of the system. Therefore, model selection involves selection of the type of processes to be studied and included in the mathematical statement. Different solution techniques are available to solve the chosen mathematical model. Analytical solutions are usually possible only for simple geometries, homogeneous aquifers, and simple boundary conditions [3].

A computer that implements the numerical model is referred as a computer code or computer model. Computer models are essential to analyze subsurface flow and contamination problems because they are designed to incorporate hydrologic parameters that an analytical model cannot incorporate. A great quantity of input data for the model must be gathered from a literature review, field investigations, and laboratory studies [4]. Nowadays, some of the most developed and used groundwater modelling softwares are Groundwater Modeling System (GMS), Tough2, Groundwater Vistas (GV) and Visual MODFLOW [5].

The use of photographic technique to capture the migration of liquids in soil in the last few years, especially the noninvasive imaging techniques has increased, bringing with it a more accurate characterization and hence understanding of transport system. Researches that applied non-invasive imaging techniques produced precise depiction and improved understanding of the multiphase system. Recently, image analysis techniques is used to investigate the migration of fluids within soils [6]. The application of digital image technique is usually used for double-porosity soil [6-14]. Rather, this research modifies the non-invasive technique that uses digital image analysis to capture successive migration of leachate through compacted laterite soil in the laboratory.

A noninvasive technique is applied in this study using digital image technique that captures successive migration of leachate through compacted laterite soil in the laboratory to simulates the leachate transportation in actual landfill. The captured digital images were fed through an image processing code using Matlab software to convert them to huesaturation-intensity (HSI) format. Surfer software then read the HSI to generate a 2D contour plot. Velocity of the leachate was then computed from the generated 2D contour plot. To further analyze the future migration of leachate into the compacted laterite soil for a very long time, a numerical model is deployed using PetraSim.

In this study, numerical modeling was applied using PetraSim, a graphical interface for the Tough2 family of simulators used to solve problems related to geothermal systems, carbon sequestration, multi-phase contaminant transport and more. Tough2 and its derivatives are recognized for their significant simulation capabilities for fluid flow and heat transfer in porous and fractured media. The Tough2 codes have been applied to problems ranging from groundwater flow to multi-component environmental remediation. PetraSim makes the power of Tough2 accessible to modelers through an interactive environment that includes mesh generation, parameter definition, and display of results. It significantly lowers the barriers to Tough2 use by freeing the analyst to focus on the model, while automatically handling the complex details of Tough2 input and output files [15].

One outstanding feature of the numerical modeling approach is the capacity for predictions to be made well into the future, thereby demonstrating the likely impacts of 
current practice on the environment and future generations [3]. In order to protect the groundwater of an area, it is necessary to understand the physical and chemical processes that occur in that area. Groundwater modeling is a tool designed to represent a simplified version of a real field site by translating these processes into mathematical terms. This permits an understanding and prediction of the system and its behaviour. The objective of this modeling is to evaluate the velocity that is calibrated based on physical laboratory experimental data to assess the benefits of model conformity, and to predict future velocity by its ability to simulate leachate flow in sanitary landfills.

\section{Material and methods}

\subsection{Material}

The laterite soil is used in this study is reddish in color and was extracted using the method of disturbed sampling from Skudai campus (Johor) which is located at latitude $1^{\circ} 33^{\prime} 39^{\prime \prime} \mathrm{N}$ and longitude 103'38'44"E of Universiti Teknologi Malaysia (UTM). The soil is classified as MV according to the British Standard classification [16]. Laboratory tests were conducted to determine the index properties of the laterite soil in accordance with British Standard as shown in Table 1.

Table 1. Index properties of laterite soil

\begin{tabular}{|c|c|}
\hline Property & Value \\
\hline Natural Moisture Content, $\%$ & 34 \\
\hline Liquid Limit, \% & 76 \\
\hline Plastic Limit, \% & 42 \\
\hline Plasticity Index, \% & 34 \\
\hline Free Swell Index, \% & 31 \\
\hline BS Classification & MV \\
\hline Specific Gravity & 2.7 \\
\hline OMC, \% & 28 \\
\hline $\mathrm{MDD}, \mathrm{Mg} / \mathrm{m}^{3}$ & 1.43 \\
\hline$\%$ Passing BS $63 \mu \mathrm{m}$ sieve & 50 \\
\hline $\mathrm{pH}$ & 9.29 \\
\hline
\end{tabular}

\subsection{Physical Modeling Method}

Basically, the digital image technique used in this research adopts the concept explained by [11]. DIT covers the migration of leachate in a $100 \mathrm{~mm}$ height of soil in acrylic column. The dimension of acrylic cylinder to form the soil column was $150 \mathrm{~mm}$ high, $100 \mathrm{~mm}$ diameter and $6 \mathrm{~mm}$ thick. The acrylic column is placed in-between two-faced mirror to provide a complete visualization of $360^{\circ}$. These mirrors were placed at $105^{\circ}$ of angle with offset distance of $0.2 \mathrm{~m}$ behind the soil column and facing the digital camera. A Hitachi 40-Watt lamp was installed overhead the soil column so that the whole setup is illuminated. The acrylic column was chosen to provide a clear visualization of leachate migration into the soil. This implies that the leachate migration through the soil is observed promptly at any point and time throughout the experiment.

A Nikon D90 digital camera was the main equipment used for image acquisition of the leachate migration at designated time intervals. The camera has a sensor size of $15.8 \mathrm{~mm}$ by $23.6 \mathrm{~mm}$ and pixel array of $3216 \times 2136$ pixels (12 megapixels) was used to operate at a minimum shutter speed and aperture. The camera is rigidly positioned with tripod and by 
using a remote control to smoothly captured images without shaking the camera. The soil column was positioned in a fixed place to avoid any movement. Since the soil columns were in circular shape, images that reflected from the camera and the two mirrors have been combined and corrected to produce a complete single flat area of interest (AOI). A paper with grid lines size of $20 \mathrm{~mm} \times 20 \mathrm{~mm}$ was used to cover the soil column to a height of $100 \mathrm{~mm}$. The grid lines are used as a reference mark on a reference image. The reference mark is required in the image registration procedure to transform any distorted image according to the actual scale image. Then a reference image was captured, and the grid lines paper was removed from the soil column.

Thereafter, leachate was poured on top of the compacted laterite soil sample in the soil column. Successive images were captured daily to monitor and record the migration behaviour. The digital image technique laboratory experimental setup is presented in Figure 1. Images for all the experiments were taken at one-day interval for one month. The duration of leachate migration from the top surface to the bottom was monitored during this period.

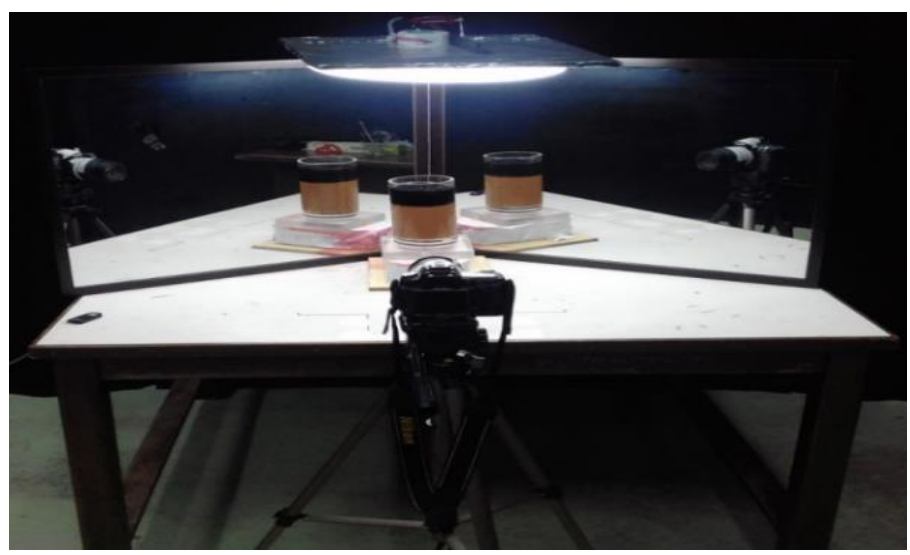

Fig. 1. Digital image laboratory setup

\subsection{Numerical Modeling Method}

The development of a model required an input data, data which are needed to characterize a flow system include hydrogeologic parameters and constitutive relations of the permeable medium, thermophysical properties of the fluids, initial and boundary conditions of the flow system, and sinks and sources [17]. The computer model adopts in this study is the PetraSim and the methodology followed are herewith. A new file is created choosing the simulator mode in Tough mode using the equation of state (EOS) in the saturated/unsaturated flow to simulate the laboratory experiment (Figure 2). An inserted model boundary condition i.e. minimum and maximum XYZ of $100 \mathrm{~mm}$ in all directions with respect to the soil sample acrylic column. 


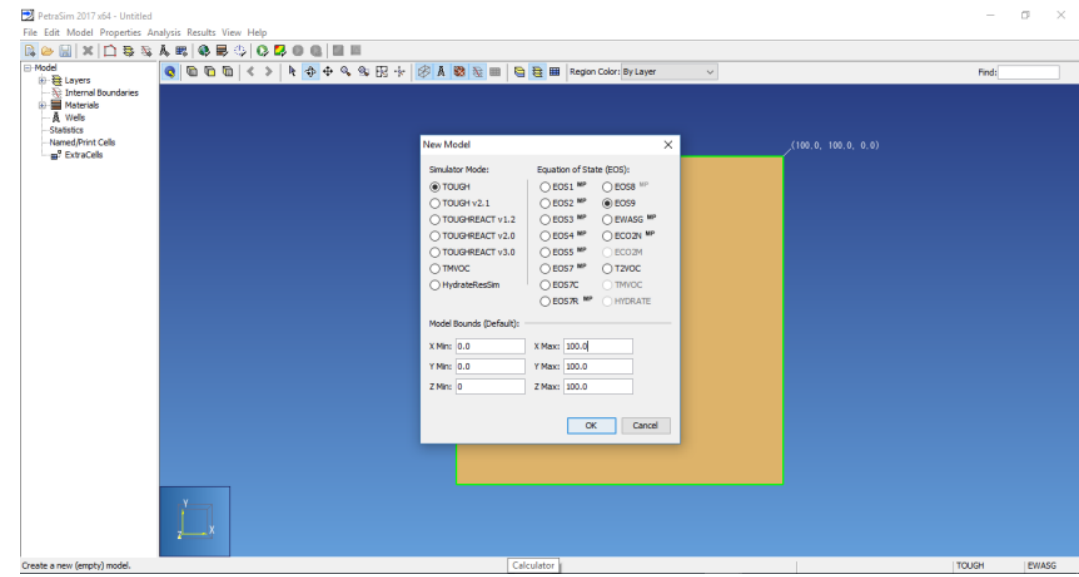

Fig. 2. New model creation using PetraSim

The next step taken was to create a regular mesh as it is rectangular simulating the grids used in the physical model. In the global properties, analysis chosen for the software to be run was Tough2. Material properties like the material name, colour, density, porosity, and permeability were applied based on the experimental work. The wet heat conductivity also referred to as specific heat is the amount of heat required to change the temperature of an object by a certain degree. The thermal conductivity of $1 \mathrm{~W} /(\mathrm{m} * \mathrm{~K})$ was selected for laterite soil [18-19]. In this research, the Corey's curve was selected, because the Brooks and Corey equation was used to calculate the unsaturated hydraulic conductivity of the laterite soil. The solution control allows for selecting the start and end time of the project. In this research, the projection time selected to predict for 50 years, enabling the designer to see the permeability projection values of the material in time. The software was run to do the simulation and plot the graph.

\section{Discussion of Results}

The results of the digital image technique and the numerical using PetraSim are presented and discussed accordingly.

\subsection{Digital Image Analysis}

The 2D Contour plot provide detail and useful information to understand the characteristic of leachate migration behaviour. The red color represents the leachate movement inside the laterite soil as presented in Figure 3. 

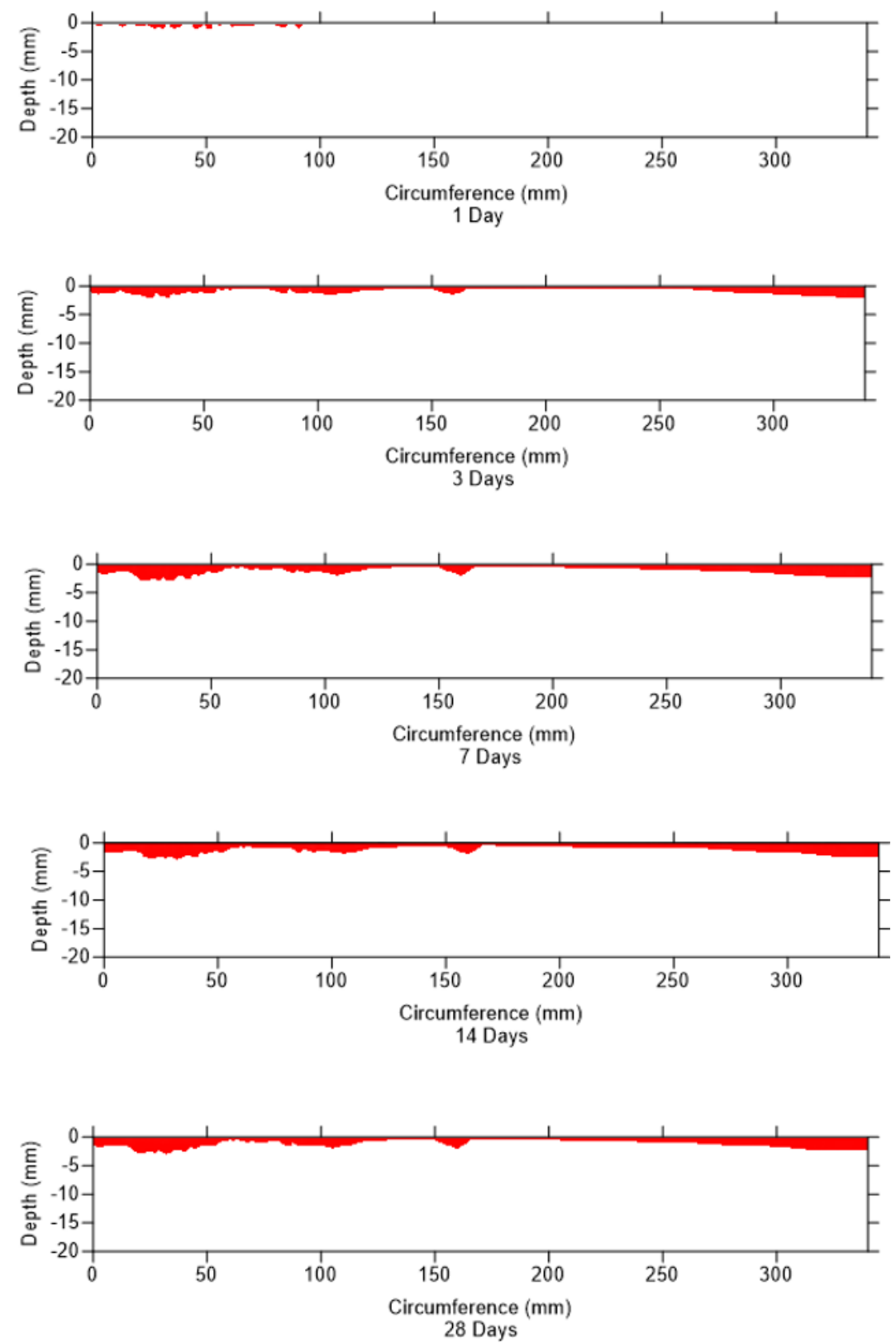

Fig. 3. Leachate migration in soil column

The leachate flow through the compacted laterite soil covering $3 \mathrm{~mm}$ depth in one month. The calculated velocity was found to be $1.24 \times 10^{-9} \mathrm{~m} / \mathrm{s}$ in one-month monitoring. This shows that the laterite soil sample specimen used in this study can be considered for liner material because it falls within the minimum range permeability value of $1 \times 10^{-9} \mathrm{~m} / \mathrm{s}$.

\subsection{Prediction of Leachate Migration}

The prediction of leachate migration was carried out to evaluate the velocity over some presumed time. Before the prediction of the velocity, the PetraSim software was 
calibrated based on physical model experimental data (i.e. digital image analysis data) in order to assess the benefits of model conformity.

The velocity of $1.38 \times 10^{-8} \mathrm{~m} / \mathrm{s}$ for day one taken from DIT was used to predict one week and one month velocities in PetraSim as shown in Figure 4 and Figure 5 respectively. From the time-velocity graphs in Figure 4, the velocity steadily decreases from $1.38 \times 10^{-8}$ $\mathrm{m} / \mathrm{s}$ to $4.5 \times 10^{-9} \mathrm{~m} / \mathrm{s}$ from the first day to seven days. Equally, Figure 5 shows a decrease in velocity from $1.38 \times 10^{-8} \mathrm{~m} / \mathrm{s}$ to $1.2 \times 10^{-9} \mathrm{~m} / \mathrm{s}$ from the first day to one month. Thereafter, the velocity remain constant after three days and seven days until one week and one month respectively, conforming with the digital image analysis result.

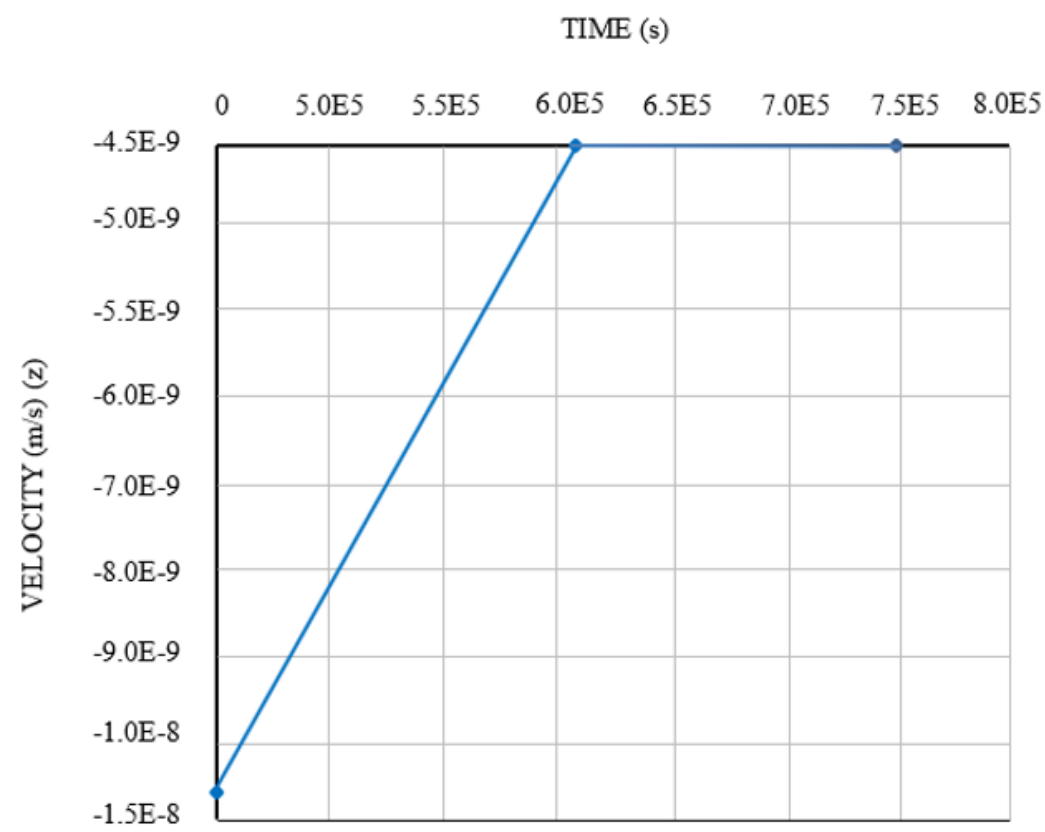

Fig. 4. Velocity versus time graph for one week 


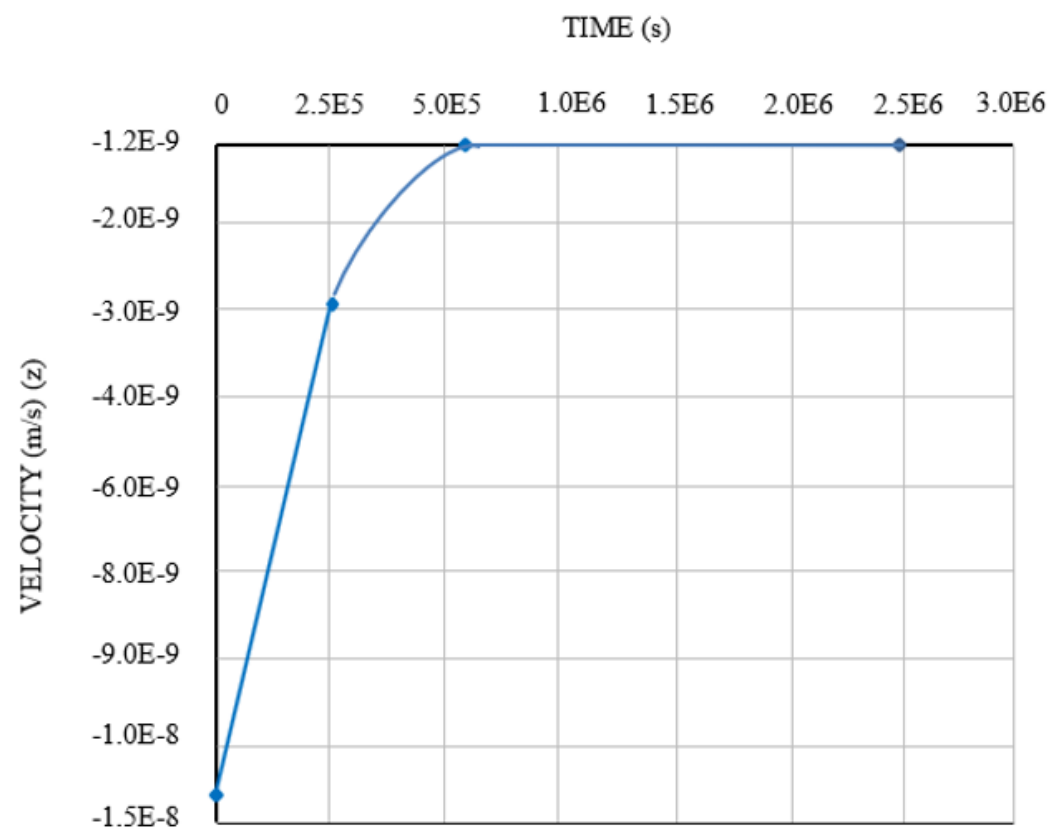

Fig. 5. Velocity versus time graph for one month

According to Holtz et al. (2011), flow in most soils is so slow that can be considered as laminar. Thus, an expression of Darcy's law is written as;

$v=k i$

Where;

$v=$ velocity

$k=$ hydraulic conductivity

$i=$ hydraulic gradient

According to USEPA (1989), the leachate height in a landfill must not exceed 300 $\mathrm{mm}$. For a soil liner $900 \mathrm{~mm}$ thick, hydraulic gradient will be around 1. Therefore, when the hydraulic gradient equals to 1 , then velocity is equals to hydraulic conductivity as expressed in equation 2 .

$$
v=k
$$

Using Figure 5, the distance covered by the leachate was estimated by applying Equation 3. The velocity of any fluid is the ratio of its distance and time covered.

$$
v=d / t
$$

Where;

$v=$ velocity

$d=$ distance

$t=$ time 
Therefore, the distance migrated by the leachate in the laterite soil sample at maximum time (one month) is approximately $2.9 \mathrm{~mm}$. This is in close line with the digital image analysis that shows the distance migrated by the leachate in the soil sample was 3 $\mathrm{mm}$. The difference between the actual and simulated is quite negligible which shows that there is design conformity as presented in the calibration curve in Figure 6.

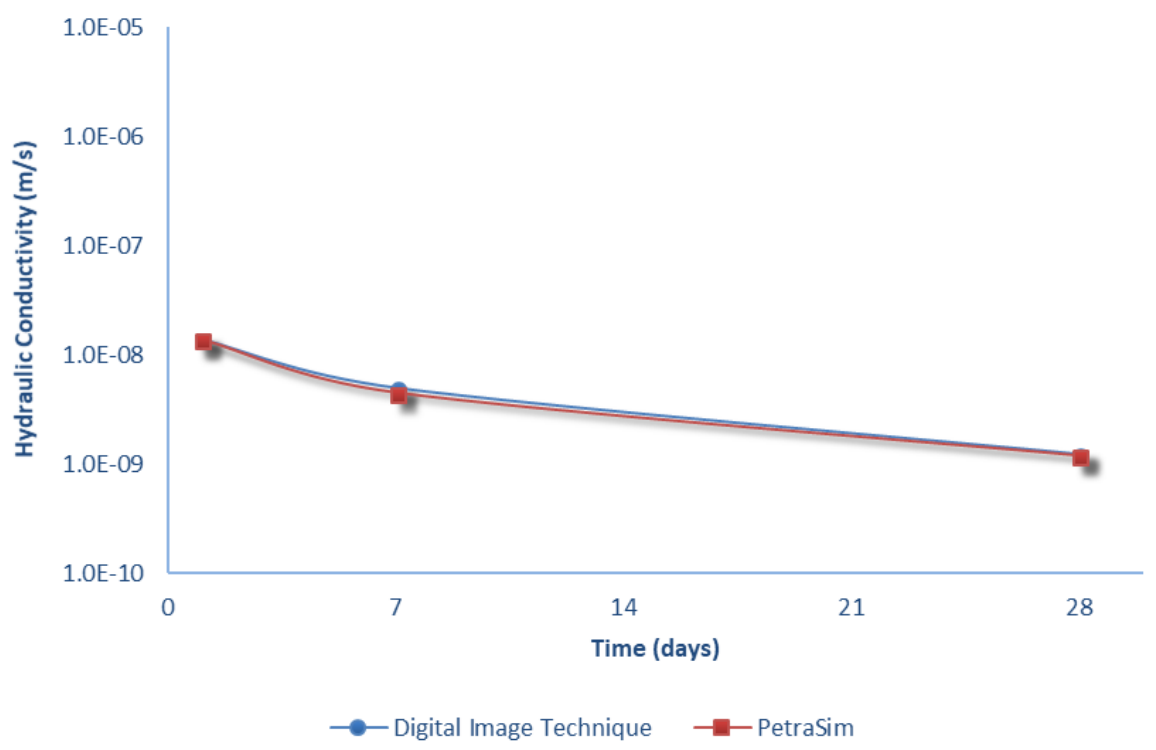

Fig. 6. Calibration curve of velocity versus time

The justification as why the migration of leachate after some time stops could be because of the medium range of $\mathrm{pH}$ (9.29) used. Researchers like [20] and [21] show that the velocity decreased in permeation period with leachate for a period of 90 days due to medium range of $\mathrm{pH}$. According to [22], leachates with $\mathrm{pH}<3$ or $>11$ are usually of the most concern. The effects of neutral, inorganic liquids may be evaluated with the GouyChapman theory [23], which states that the thickness $(T)$ of the diffuse double layer varies with the dielectric constant of the pore fluid $(D)$, the electrolyte concentration $\left(n_{o}\right)$, and the cation valence $(v)$ as follows:

$$
T \propto\left[\frac{D}{n_{n} v^{2}}\right]^{1 / 2}
$$

For solutions containing mainly water, the dielectric constant of the liquid is relatively constant, and thus the main parameters are $n_{o}$ and $v$. As the diffuse double layer of adsorbed water and cations expands, hydraulic conductivity decreases because flow channels become constricted. Therefore, aqueous solutions with few electrolytes, e.g., distilled water, tend to expand the double layer and to produce low hydraulic conductivity. Similarly, [24] stated that MSW leachate can cause a slight decrease in hydraulic conductivity of inactive clays probably due to $\mathrm{Na}^{+}$adsorption, double layer expansion and bacteria clogging. Additionally, as result of compaction, most of the pores in the soil are rendered ineffective (i.e. non-interconnected) thereby resulting in difficulty for the leachate to move further. 
Furthermore, to predict the hydraulic conductivity parameter for 50 years, a simulation of the velocity that was calibrated based on physical model experimental data was used as validation. From the time-velocity graphs in Figure 7, the velocity decreases from $1.2 \times 10^{-9} \mathrm{~m} / \mathrm{s}$ to $6 \times 10^{-10} \mathrm{~m} / \mathrm{s}$ in 1 month to 50 years respectively. This difference could also be due to susceptibility of the laterite soil particles to swelling, resulting in its rearrangement and reorientation making it more difficult for the water to pass through. According to [25], it is required for soil barrier materials to have high swelling potential to achieve low hydraulic conductivity and to fill voids and fractures to achieve an improved impermeable zone around the landfill. The laterite soil used has a free swelling index of $31 \%$ which shows that it possesses moderately high self-sealing abilities when in contact with leachate.

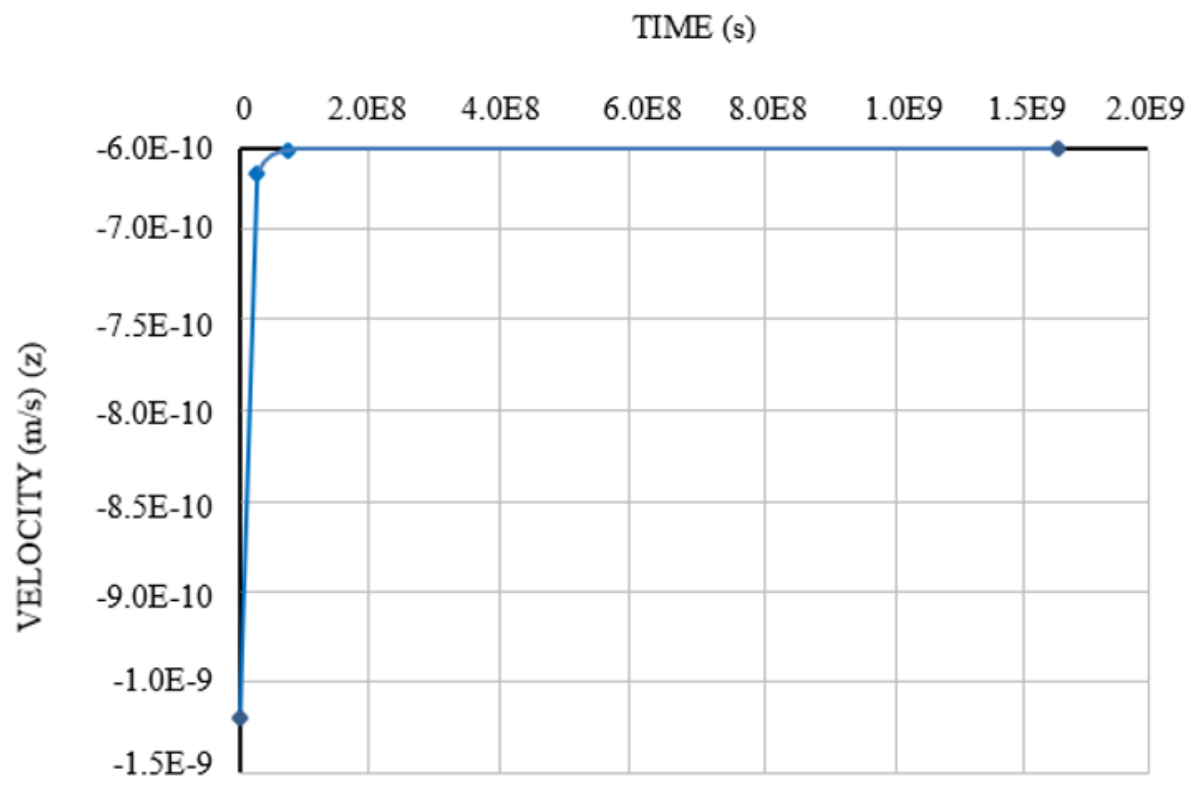

Fig. 7. Velocity versus time graph for 50 years

\section{Conclusion}

A full-scale experiment would be prohibitively costly and time consuming. The only feasible recourse therefore is to construct a model, which reasonably portray the behaviour of the full-scale system and simulate the relevant physical parameters and describes the overall significant characteristics of the transport phenomena. In this study, a laboratory experimentation was conducted on compacted laterite soil. The digital image processing technique using Matlab routine and Surfer software was applied to show the leachate migration behaviour in the soil column physical model. The results of the laboratory experiments determined through the observation of leachate percolation into the test samples are compared and the rate of velocity calculated. The numerical projection reveals that the laterite soil is well compatible with the leachate and can impede its flow with time to $6 \times 10^{-10} \mathrm{~m} / \mathrm{s}$. Therefore, the laterite soil used in this study provides the recommended 
hydraulic conductivity which can be used as hydraulic barriers in waste containment applications.

The authors would like to acknowledge the financial support of this research by Universiti Teknologi Malaysia under GUP Tier 1 vote number R.J130000.2522.20H53. Also, express appreciation to all who are involved either directly or indirectly.

\section{References}

1. C. Kumar, Groundwater modelling software — capabilities and limitations, J Environ Sci Toxicol Food Technol, vol. 1, no. 2, pp. 46-57 (2012).

2. C. Kumar, Groundwater flow models, Scientist 'E1'National Institute of Hydrology Roorkee-247667 (Uttaranchal) publication (2002).

3. R. P. Kumar, G. Dodagoudar, S. Quadri, Contaminant Transport Modelling Through Landfill Liners, in Indian Geotechnical Conference - 2010, GEOtrendz. December 1618, 2010. IGS Mumbai Chapter \& IIT Bombay (2010).

4. E. Mehnert, B. R. Hensel, W. Brookfield, Coal combustion by-products and contaminant transport in groundwater. pp. 161-171 (1996).

5. S. Duriez, "On the Use of Groundwater Contaminant Transport Modelling in Risk Assessments," Department of Civil and Environmental Engineering, Division of GeoEngineering, Engineering Geology, Chalmers University of Technology, SE-412 96 Göteborg, Sweden (2005).

6. M. Y. Alazaiza, S. K. Ngien, M. M. Bob et al., Assessment of the behaviour of soil structure in double-porosity kaolin media using light transmission visualization (LTV) method, International Journal of Geotechnical Engineering, pp. 1-5 (2016).

7. M. Y. Alazaiza, S. K. Ngien, M. M. Bob et al., Influence of Macro-pores on DNAPL Migration in Double-Porosity Soil Using Light Transmission Visualization Method, Transport in Porous Media, pp. 1-21 (2017).

8. M. Y. Alazaiza, S. K. Ngien, M. B. Mustafa et al., Application of Light Reflection Method to Observe DNAPL Movement in Different Soil Media. The National Conference for Postgraduate Research 2016, Universiti Malaysia Pahang, (2016).

9. M. Y. Alaziaza, S. K. Ngien, M. M. Bob et al., Investigation of Light Non-Aqueous Phase Liquid Migration Single and Double-Porosity Soil Using Light Transmission Visualization Method (LTV), The National Conference for Postgraduate Research, Universiti Malaysia Pahang (2016).

10. L. K. Foong, N. A. Rahman, M. Z. Ramli, A Laboratory study of vibration effect for deformable double-porosity soil with different moisture content, Malaysian Journal of Civil Engineering, vol. 28 no. 3, pp. 207-222 (2016).

11. R. Sa'ari, N. Rahman, Z. Yusof et al., Application of digital image processing technique in monitoring LNAPL migration in double porosity soil column, Jurnal Teknologi, vol. 72, no. 3, pp. 23-29 (2015).

12. S. K. Ngien, N. A. Rahman, M. M. Bob et al., Observation of light non-aqueous phase liquid migration in aggregated soil using image analysis, Transport in porous media, vol. 92, no. 1, pp. 83-100 (2012).

13. S. A. Kamaruddin, W. N. A. Sulaiman, M. P. Zakaria et al., Laboratory simulation of LNAPL spills and remediation in unsaturated porous media using the image analysis technique: a review. pp. 1-7 (2011).

14. S. Kamarudin, W. N. A. Sulaiman, N. Rahman et al., A review of laboratory and numerical simulations of hydrocarbons migrations in subsurface environments, Journal of Environmental Science and Technology, vol. 4, no. 3, pp. 191-214 (2011).

15. www.rockware.com. Rockware.com/product/petrasim. Access on 01/01/2018. 
16. BSI, "Methods of Testing Soil for Civil Engineering Purposes (BS 1377:Part 1-9). British Standards Institute, London.," 1990.

17. K. Pruess, C. Oldenburg, G. Moridis, TOUGH2 user's guide version 2, Lawrence Berkeley National Laboratory (2012).

18. H. Bal, Y. Jannot, S. Gaye et al., Measurement and modelisation of the thermal conductivity of a wet composite porous medium: laterite based bricks with millet waste additive, Construction and Building materials, vol. 41, pp. 586-593 (2013).

19. b. R. Ruzaimah, b. A. Abd Halid, b. M. N. Mohammad Soffi et al., Thermal and Structural Properties of Compressed Earth Brick (Laterite Soil), Proceedings of the International Postgraduate Conference on Engineering (IPCE 2010) 16 - 17 October 2010, Perlis, Malaysia (2010).

20. G. Moses, "Hydraulic and contaminant transport performance of compacted bagasse ash treated foundry sand for use in waste containment facilities," Ahmadu Bello University, Zaria, Nigeria, 2012.

21. O. A. Eberemu, "Evaluation of bagasse ash treated lateritic soil as a suitable material for waste landfill barrier (liner and cover)," civil engineering, Ahmadu Bello University, Zaria, Nigeria, 2008.

22. D. E. Daniel, Geotechnical practice for waste disposal: Springer Science \& Business Media, DOI:10.1007/978-1-4615-3070-1, (2012).

23. K. J. Mitchell, K. Soga, Fundamentals of Soil Behavior: 3rd Edition, John Wiley and Sons Inc., New Jersey, (2005).

24. K. R. Rowe, Clayey barrier systems for waste disposal facilities: E \& FN Spon Lond, (1995).

25. A. A. Amadi, Swelling characteristics of compacted lateritic soil-bentonite mixtures subjected to municipal waste leachate contamination, Environmental earth sciences, vol. 70, no. 6, pp. 2437-2442 (2013). 